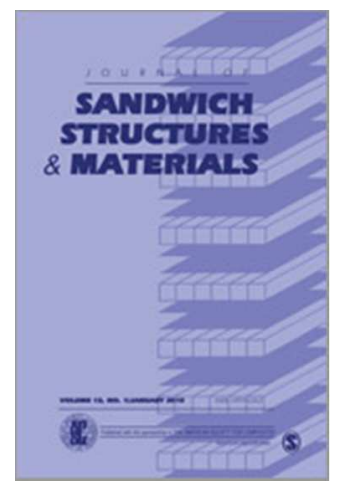

\title{
Indentation failure of foam cored sandwich structures subjected to elevated temperatures
}

\begin{tabular}{|c|c|}
\hline Journal: & Journal of Sandwich Structures and Materials \\
\hline Manuscript ID & JSSM-17-0174 \\
\hline Manuscript Type: & Standard Article \\
\hline Keywords: & $\begin{array}{l}\text { sandwich structures, foam core material, indentation failure, elevated } \\
\text { temperatures, Winkler foundation model }\end{array}$ \\
\hline Abstract: & $\begin{array}{l}\text { This research explores the detrimental effect of elevated temperatures on } \\
\text { local indentation failure of polymer foam cored sandwich structures with } \\
\text { laminated glass fibre reinforced epoxy face sheets. A simple analytical } \\
\text { model to predict the critical indentation failure load at elevated } \\
\text { temperatures is presented and validated against experimental } \\
\text { observations. For this purpose, a sandwich beam loaded in three-point } \\
\text { bending with an induced through-thickness elevated temperature profile, } \\
\text { was studied experimentally and by means of analytical and finite element } \\
\text { models. In the experiment, the through-thickness temperature gradient } \\
\text { was induced with an infrared lamp pointing on the top face sheet, while the } \\
\text { local displacement and strain fields near the applied point load were } \\
\text { recorded by digital image correlation. The analytical model proposed, which } \\
\text { accounts for temperature degraded/reduced foam core properties, } \\
\text { superimposes the local response, approximated by the classical Winkler } \\
\text { foundation model, and the global response, obtained by sandwich beam } \\
\text { theory. The comparative study has shown that the critical load causing } \\
\text { core crushing failure reduces significantly with elevated temperatures by as } \\
\text { much as } 50 \text { \% at an elevated temperature of } 90 \text { o C. It is shown that the } \\
\text { simple analytical model can predict the local deflections and core stresses } \\
\text { of foam cored composite sandwich structures subjected to simultaneous } \\
\text { localised mechanical loading and elevated temperatures. Thus, the } \\
\text { analytical model can be used as a preliminary design tool to determine the } \\
\text { critical core crushing load at elevated temperatures. }\end{array}$ \\
\hline
\end{tabular}




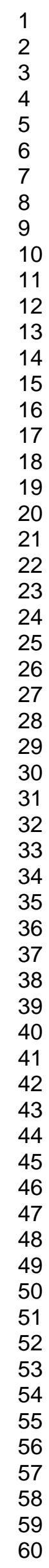

SCHOLARONE $^{\text {It }}$

Manuscripts

hhttp://mc.manuscriptcentral.com/jssm 
Original Article

Corresponding Author:

Tobias Laux, Faculty of Engineering and the Environment, University of Southampton, Highfield, Southampton SO17 1BJ, UK

Email: t.laux@soton.ac.uk

\title{
Indentation failure of foam cored sandwich structures subjected to elevated temperatures
}

\author{
Tobias Laux ${ }^{1}$, Ole T Thomsen ${ }^{1}$ \\ ${ }^{1}$ Faculty of Engineering and the Environment, University of Southampton, Highfield Campus, \\ Southampton, UK
}

\section{Abstract}

This research explores the detrimental effect of elevated temperatures on local indentation failure of polymer foam cored sandwich structures with laminated glass fibre reinforced epoxy face sheets. A simple analytical model to predict the critical indentation failure load at elevated temperatures is presented and validated against experimental observations. For this purpose, a sandwich beam loaded in three-point bending with an induced through-thickness elevated temperature profile, was studied experimentally and by means of analytical and finite element models. In the experiment, the through-thickness temperature gradient was induced with an infrared lamp pointing on the top face sheet, while the local displacement and strain fields near the applied point load were recorded by digital image correlation. The analytical model proposed, which accounts for temperature degraded/reduced foam core properties, superimposes the local response, approximated by the classical Winkler foundation model, and the global response, obtained by sandwich beam theory. The comparative study has shown that the critical load causing core crushing failure reduces significantly with elevated temperatures by as much as $50 \%$ at an elevated temperature of $90{ }^{\circ} \mathrm{C}$. It is shown that the simple analytical model can predict the local deflections and core stresses of foam cored composite sandwich structures subjected to simultaneous localised mechanical loading and elevated temperatures. Thus, the analytical model can be used as a preliminary design tool to determine the critical core crushing load at elevated temperatures.

Keywords

sandwich structures, foam core material, indentation failure, elevated temperatures,

\section{Introduction}

Lightweight composite sandwich structures with glass fibre reinforced polymer (GFRP) face sheets and polymer foam core materials (such as polyvinyl chloride - PVC) are widely used for structural applications across, e.g. the marine, transportation and energy industries. They are valued for their excellent stiffness to weight ratio combined with their affordability for low to medium cost applications [1]. However, they are prone to indentation failure when localised loading is applied and they are sensitive to elevated temperatures, because the typically used foam cores display significant softening and reduction of stiffness and strength already in the temperature range of 50 to $70{ }^{\circ} \mathrm{C}$, which is well within the service environment 
of typical applications such as high speed boats and train structures or wind turbine blades that are exposed to e.g. sun light or heat emission of machinery.

Growing concern in industry and academia has led to research into the thermal behaviour of PVC foam and the implications for foam cored sandwich structures. Zhang et al. [2] experimentally obtained the temperature dependency of the tensile and compressive Young's moduli of DIAB Divinycell cross-linked PVC H100, H130 and H200 [3] foam cores in the temperature range of 25 to $90{ }^{\circ} \mathrm{C}$. Taher et al. extended the characterization of Divinycell $\mathrm{H} 100$ at elevated temperatures with experimental measurements of the shear modulus and strength [4] and the compressive collapse strain and strength in the through-thickness and inplane directions [5].

Based on accurate measurements of the temperature dependent foam core properties, Zhang et al. $[6,7]$ looked at the implication of temperature reduced/degraded foam core properties on structural components and investigated the failure mode of face sheet wrinkling and the bending behaviour of foam cored sandwich structures leading to core shear failure under combined mechanical and thermal loading. In parallel, Palleti et. al [8] investigated the loadresponse of a foam cored sandwich beam subjected to elevated temperatures with a special emphasis on the use of a nonlinear FE material model based on the generalized Hill anisotropic plasticity model to capture the foam core's highly nonlinear response at elevated temperatures. In [6-8] foam cored sandwich beams were loaded in three- or four-point bending while a through-thickness temperature gradient was induced by an infrared lamp pointing at the top face sheet. This is a very realistic scenario that can be found wherever a heat source, such as sun radiation or machinery, is positioned on one side of a sandwich panel. Furthermore, digital image correlation (DIC) has been used to capture the through-thickness displacement and strain fields.

Indentation failure of sandwich structures at room temperature has been studied extensively and several analytical modelling approaches have been proposed. The simplest analytical indentation models are based on the superposition principle of the global bending response, obtained by sandwich beam or panel theory [1], with the local response obtained by application of the Winkler foundation model [9]. The latter models the core as continuously distributed tension/compression springs with an associated foundation modulus $K_{z}$. Thomsen $[10,11]$ extended the simple model to a so called two parameter model, which introduced shear springs to allow for local shear stresses in the top face sheet to core interface. The two approaches are compared with the conclusion that local shear stresses can be neglected for indentation wave lengths $\lambda$ higher than 50 to $60 \mathrm{~mm}$, which is the case for most main stream composite sandwich panels. Olsson [12] presented an indentation model very similar to Thomsen's Winkler model but additionally proposed two different foundation moduli for thick cores to calculate local deflections and stresses respectively. Both authors highlighted the dependency of the foundation modulus $K_{z}$ on the thickness of the core and proposed different formulations for thin and thick cores. Frostig and Thomsen [13] introduced a higher order sandwich beam theory which is capable of simultaneously predicting the local and global bending by relaxing the fundamental assumption of classical sandwich beam theory, i.e. that a section of the core remains planar and that the distance between the face sheets is constant when loaded. However, the theory is mathematically complex and is not well suited to formulate a simple tool that could be used in a design environment, which is the goal of this work.

The literature review has shown, that foam cored composite sandwich structures are increasingly being used for application that involve elevated temperatures (up to about $90{ }^{\circ} \mathrm{C}$ ). It was found, that all the research identified in open literature on indentation failure has been conducted at room temperature, whereas indentation failure at elevated temperature has never 
been addressed before. The present study fills the knowledge gap and addresses the problem of localized loading of foam cored sandwich structures subjected to elevated temperatures. The aim is to improve the understanding of the indentation mechanism at elevated temperatures, and to develop guidelines and methodologies for the design of foam cored sandwich structures at elevated temperature to avoid premature failure due to core crushing. Additional details of the research not reported in this paper can be found in [14].

\section{Methodology}

\section{Setting the scene}

Figure 1 illustrates the studied scenario of a sandwich beam with a temperature gradient $\left(T_{t}-\right.$ top face sheet temperature, $T_{b}$ - bottom face sheet temperature) imposed through the core thickness, leading to degraded or reduced mechanical properties of the foam core. The reduced properties are the core Young's moduli $E_{c}$, the core shear moduli $G_{c}$, the core strengths $X_{c}$ and the foundation modulus $K_{z}$. The simple three-point bending configuration allows the simultaneous study of the global bending of the sandwich beam and the local bending of the top face sheet near the localised load. In the following, indentation failure is defined as the state where the through thickness compressive stress or strain in the core reaches the compressive through-thickness strength or strain to failure of the core at the top face sheet to core interface at midspan (red half-circle).

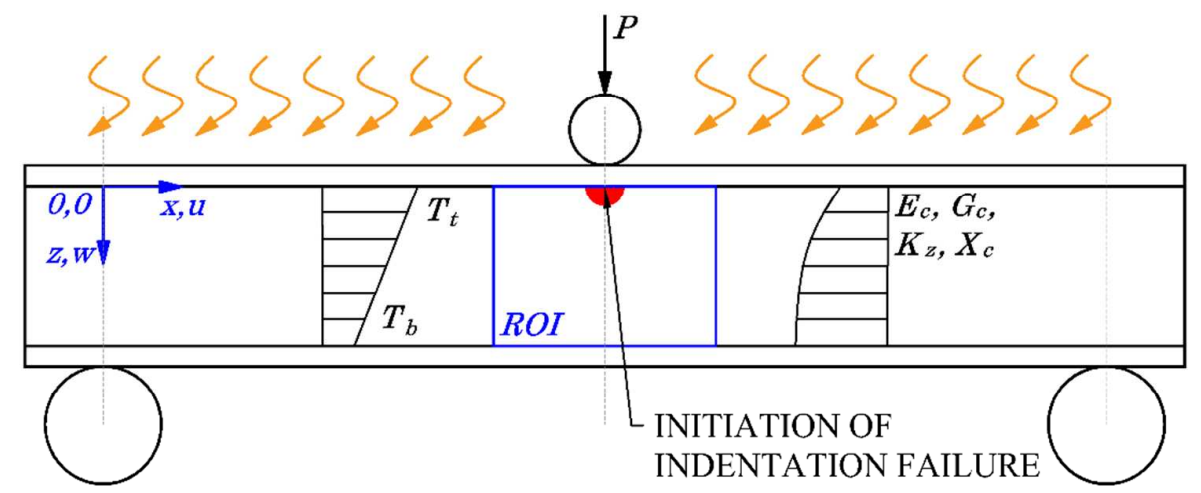

Figure 1. Sandwich beam loaded in three-point bending with an applied temperature gradient

Divinycell H100 from DIAB was selected as core material due to its known temperature dependency derived in previous studies. The elastic properties given in [2-4] were reduced according to the experimentally derived regression formula [7]:

$$
\frac{E(T)}{E\left(T_{0}\right)}=\frac{G(T)}{G\left(T_{0}\right)}=-3.19 * 10^{-6} T^{3}+4.24 * 10^{-4} T^{2}-2.27 * 10^{-2} T+1.36
$$

The relevant through-thickness strength and strain to failure properties at the investigated temperature cases were extracted from the normalized design charts in [4,5]. Table 1 lists all employed H100 foam core material properties. 
Table 1. DIAB Divinycell H100 foam core properties [2-8].

\begin{tabular}{|c|c|c|c|c|c|c|}
\hline \multicolumn{2}{|c|}{ Mechanical property } & \multirow{2}{*}{$\frac{25^{\circ} \mathrm{C}}{132}$} & \multirow{2}{*}{$\frac{50^{\circ} \mathrm{C}}{117}$} & \multirow{2}{*}{$\frac{70^{\circ} \mathrm{C}}{100}$} & \multicolumn{2}{|l|}{$90^{\circ} \mathrm{C}$} \\
\hline $\mathrm{E}_{\mathrm{c}}$ & $\begin{array}{l}\text { Through-thickness compressive } \\
\text { modulus }\end{array}$ & & & & 56 & {$[\mathrm{MPa}]$} \\
\hline$X_{c}$ & $\begin{array}{l}\text { Through thickness compressive } \\
\text { strength }^{1}\end{array}$ & $2 / 1.65$ & $1.78 / 1.47$ & $1.4 / 1.15$ & $0.98 / 0.81$ & {$[\mathrm{MPa}]$} \\
\hline$\varepsilon_{\mathrm{c}}$ & $\begin{array}{l}\text { Through-thickness compressive } \\
\text { strain to failure }\end{array}$ & 0.0218 & 0.0218 & 0.0218 & 0.0262 & {$[-]$} \\
\hline $\mathrm{G}_{\mathrm{xz}}$ & $\begin{array}{l}\text { Through-thickness shear } \\
\text { modulus }\end{array}$ & 32 & 28 & 24 & 14 & {$[\mathrm{MPa}]$} \\
\hline $\mathrm{S}_{\mathrm{xz}}$ & $\begin{array}{l}\text { Through-thickness shear } \\
\text { strength }^{1}\end{array}$ & $1.6 / 1.4$ & NA & NA & NA & {$[\mathrm{MPa}]$} \\
\hline$v_{\mathrm{xz}}$ & $\begin{array}{l}\text { Through-thickness Poisson's } \\
\text { ratio }\end{array}$ & 0.4 & & & & {$[-]$} \\
\hline$E_{x}, E_{y}$ & In-plane young's moduli & 58 & 51 & 44 & NA & {$[\mathrm{MPa}]$} \\
\hline $\mathrm{T}_{\mathrm{g}}$ & Glass transition temperature & 85 & & & & {$\left[{ }^{\circ} \mathrm{C}\right]$} \\
\hline
\end{tabular}

The face sheets were laminated from a unidirectional GFRP epoxy prepreg system RP-528 from PRF composites with a fibre volume fraction of approximately $51 \%$ and a nominal fibre weight of $300 \mathrm{~g} / \mathrm{m}^{2}$. GFRP prepregs were chosen for their consistent mechanical properties and the high glass transition temperature $\left(T_{g}=100{ }^{\circ} \mathrm{C}\right)$, ensuring thermal stability of the face sheets during the experiments at elevated temperatures. The laminates were cured in an autoclave at $120^{\circ} \mathrm{C}$ for 1 hour at 6.2 bars per the manufacturer's product data sheet [15]. The loss of face sheet stiffness $E_{f}$ was estimated to lie between $3-4 \%$ at $90{ }^{\circ} \mathrm{C}$ according to Barbero [16] and was judged negligible for the purpose of this work.

The fabricated face sheet laminates were bonded to the foam core using SA80 $250 \mathrm{~g} / \mathrm{m}^{2}$ adhesive epoxy film from Gurit [17]. The adhesive film (Max $T_{g}=99^{\circ} \mathrm{C}$ at cure Temperature of $120^{\circ} \mathrm{C}$ ) ensured a bond line with a constant thickness (approx. $0.2 \mathrm{~mm}$ ) between core and face sheets. The constituents were cured together in a vacuum bag at 1 bar and at a temperature of $80^{\circ} \mathrm{C}$ for 12 hours. The low cure temperature minimized the risk of altering the foam core properties during the manufacturing process by exceeding the glass transition temperature of the constituent materials.

A preliminary version of the analytical model presented in the next section of this paper was used to design a sandwich beam specimen that would be suitable for the study of core indentation failure. Sandwich beams show a range of competing failure modes, which typically are core shear failure, face sheet fracture, face sheet wrinkling and indentation [1]. To achieve a sandwich beam configuration that would fail exclusively due to indentation failure (rather than any of the other competing modes of failure), the analytical model was used to select suitable geometrical and material parameters. The investigated sandwich beam should closely replicate a real structure; hence, its span was maximized in the bounds of the 
available three-point bending rig. A realistic face sheet thickness for e.g. marine, transportation or wind turbine blades of a minimum of $2 \mathrm{~mm}$ was required which was achieved by stacking ten RP-528 layers. Having established these initial parameters, an iterative design process based on the analytical model at room temperature was adopted as shown in Figure 2 to determine the face sheet laminate layup and the core thickness.

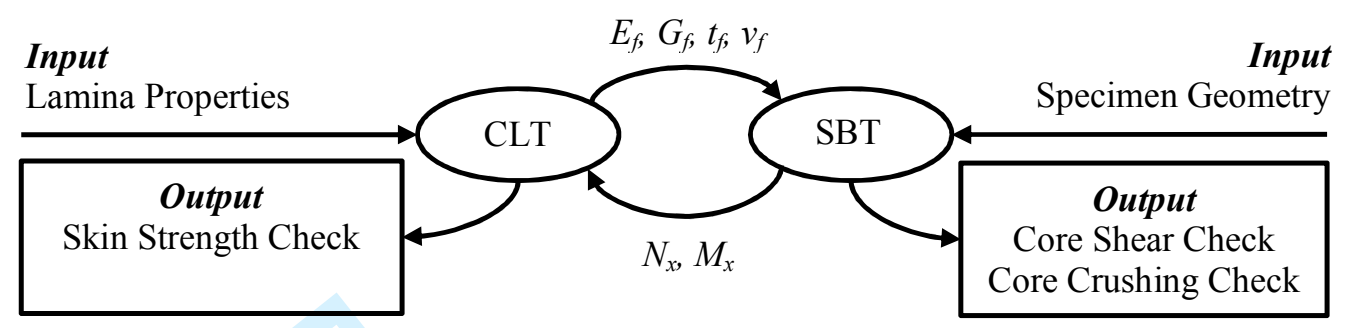

Figure 2. Iterative design process adopted for the sandwich specimen design.

Firstly, classical lamination theory (CLT) was utilized to determine the elastic properties of a face sheet laminate candidate, and these were then fed into the extended sandwich beam theory code (SBT) as described in the next section. The SBT code provided a direct check of the core shear and core crushing stresses and in addition provided the load case for the critical top face sheet consisting of a compressive normal load $N_{x}$ and a local bending moment $M_{x}$ relative to the midsurface of the top face sheet. Both loads were fed back into the CLT code where a first ply failure (FPF) strength analysis based on the Tsai-Wu composite failure theory [18] was performed. The process was iterated until a specimen design was identified in which failure was predominately initiated through indentation and core crushing. The outcome was a sandwich specimen with a span of $400 \mathrm{~mm}$ between the rollers, an additional $25 \mathrm{~mm}$ overhang on each side of the supports, and a core thickness of $45 \mathrm{~mm}$. A face sheet lay-up of $[0]_{10}$ with a cured thickness of $2.27 \mathrm{~mm}$ proved favourable as premature face sheet failure through inter fibre matrix cracking (which would be highly likely for face sheets with angle ply stacking sequence) was practically eliminated. The relatively thick core ruled out core shear failure and increased the local indentation deflections relative to the global sandwich beam deflection, thus providing a specimen configuration well suited for conducting DIC measurements of the local displacement and strain fields.

The face sheet mechanical properties calculated by CLT were confirmed by a tensile test and the results are shown and compared to the predictions in Table 2.

Table 2. Experimental and theoretical mechanical properties of the laminated face sheets ([0] $]_{10}$ of RP528 [15] with an average laminate thickness of $2.27 \mathrm{~mm}$ )

\begin{tabular}{lllll}
\hline & $E_{\mathrm{f}}[\mathrm{GPa}]$ & $v_{\mathrm{f}}[-]$ & $\varepsilon_{\mathrm{f} \text { fail }[-]}$ & FPF Load $[\mathrm{N} / \mathrm{mm}]$ \\
\hline Mean & 41.855 & 0.317 & 0.022 & 2047.486 \\
Std Dev & 0.853 & 0.008 & 0.005 & 502.604 \\
$\begin{array}{l}\text { Number of } \\
\text { Tests }\end{array}$ & 6 & 3 & 3 & 3 \\
$\begin{array}{l}\text { CLT } \\
\text { Prediction }\end{array}$ & 43.067 & 0.28 & 0.028 & 2701.000 \\
\hline
\end{tabular}


Table 2 shows, that the measured Young's modulus $E_{f}$ and the Poisson's ratio $v_{f}$ are in good agreement with the CLT predictions based on material properties taken from the material data sheet. The observed maximum failure strain $\varepsilon_{f f a i l}$ and the First Ply Failure load display larger scatter due to premature tab debonding and longitudinal fibre splitting. Finally, Figure 3 shows the selected specimen design as manufactured.

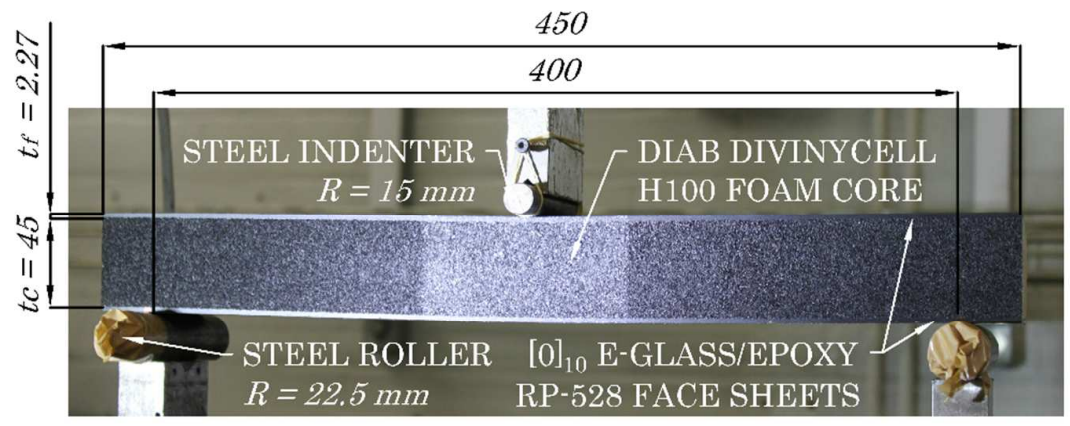

Figure 3. Final sandwich beam specimen design with an average width of $b=56.9 \mathrm{~mm}$.

Based on the obtained face sheet Young's modulus $E_{f}$, the bending stiffness per unit width of the top face sheet $D_{f}$ is obtained for the selected unidirectional laminate as:

$$
D_{f}=\frac{t_{f}^{3}}{12} E_{f}
$$

\section{Analytical Model}

The model assumes that the total response at the top face sheet of a locally loaded sandwich beam can be obtained by superimposing local and global responses as illustrated in Figure 4 $[11]$.

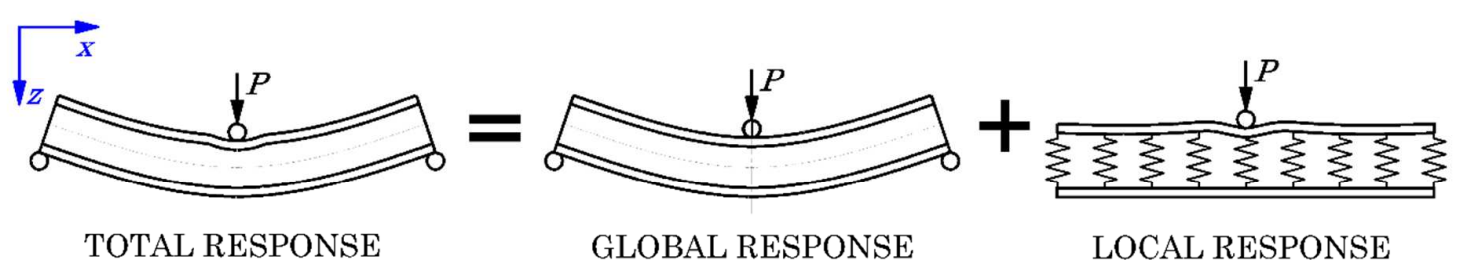

Figure 4. Superposition principle - fundamental assumption for the analytical model.

The global response is computed using classical sandwich beam theory [1]. The sandwich beam bending stiffness $D$ and the shear stiffness $S$ are calculated based on their generalized forms in equations (3) and (4) to accommodate the variable through-thickness core properties $\left(E_{c}\right.$ and $\left.G_{c}\right)$ as a result of the induced temperature gradient.

$$
\begin{aligned}
& D=b \int E(z) z^{2} d z \\
& S=b \int G(z) d z
\end{aligned}
$$

Based on the above computed stiffness and the known global bending and shear force diagrams along the simply supported beam in three-point bending [1], the global displacement and the global stress and strain fields are obtained. The classical sandwich beam theory 
assumes linear elastic behaviour to failure and small displacements, rotations and strains and is based on the restrictive assumption that the distance between the top and bottom face sheets is constant (sandwich beam thickness does not change during loading and deformation). Furthermore, the theory includes the effect of transverse shear but it is assumed that the beam cross sections remain planar after deformation, which renders the theory incapable of correctly accounting for localised loading. Thus, the local response is approximated by adopting the Winkler foundation model which considers the top face sheet to be supported by an elastic foundation, modelled as continuously distributed tension/compression springs as illustrated in Figure 5 [9-12].

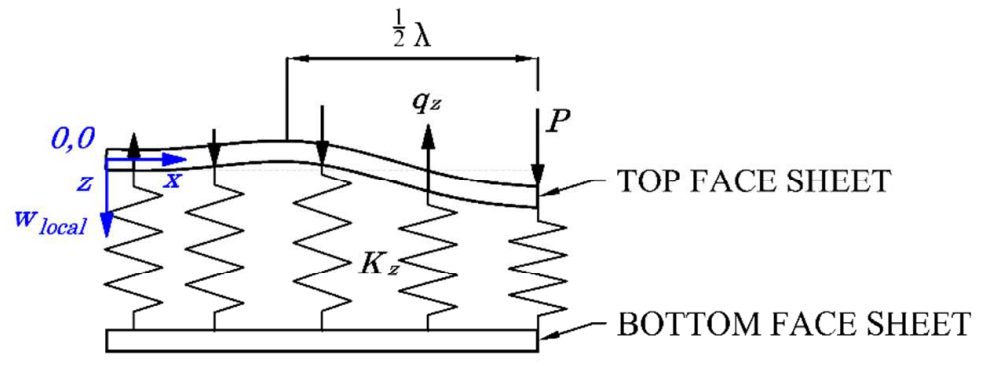

Figure 5. Illustration of the Winkler foundation model with the foundation modulus $K_{z}$, the interfacial normal stresses $q_{z}$, and the indentation wave length $\lambda$.

The interface shear stresses can be neglected as long as the indentation wave length $\lambda$ is significantly larger than the face sheet thickness, where the indentation wave length can be expressed by [11]:

$$
\lambda=2 \pi \sqrt[4]{\frac{4 D_{f}}{K_{z}}}
$$

For the sandwich beam considered in this study, the indentation wave length is $85 \mathrm{~mm}$. This is much larger than the face sheet thickness $(2.27 \mathrm{~mm})$ and accordingly the choice of the Winkler foundation model over Thomsen's two parameter model (which effectively is equivalent to a so-called Pasternak two parameter foundation model) [11] is justified for the investigated sandwich beam configuration.

The Winkler foundation model predicts the local deflection $w_{\text {local }}$ of the top face sheet, which is then superimposed to the global sandwich beam response. In addition, the model predicts the through-thickness interfacial normal stresses $q_{z}$ at the interface between the core and the indented top face sheet which are not accounted for in the sandwich beam theory. The elastic foundation modulus per unit width $K_{z}$, which governs the interaction between the loaded face sheet and the supporting core material and thereby the local response, is computed by the semi-empirical formula given in equations (6). The expression for $K_{z}$ is derived from comparison to the $2 \mathrm{D}$ elasticity solution of the idealised problem [11].

$$
K_{z}=0.28 E_{c}^{A V G} \sqrt[3]{\frac{E_{c}^{A V G}}{D_{f}}}
$$

This research suggests to use $E_{c}^{A V G}$ given in equation (7), which is the average troughthickness compressive Young's modulus of the foam core, to compute the foundation modulus of the core at elevated temperatures. Thus, the reduced through-thickness foam core 
properties are accounted for in the computation of the local response at elevated temperature and basically softens (reduces) the foundation modulus $K_{z}$.

$$
E_{c}^{A V G}=\frac{1}{t_{c}} \int E_{c}(z) d z
$$

$K_{z}$ is then used to solve for the local deflection $w_{\text {local }}$ of the top face sheet with respect to its own neutral axis, which is described by the solution given in equations (8) of the governing $4^{\text {th }}$ order differential equation described in [11].

$$
\begin{aligned}
& w_{\text {local }}(x)=C_{1} \sinh (\kappa x) \sin (\kappa x)+C_{2} \sinh (\kappa x) \cos (\kappa x) \\
& +C_{3} \cosh (\kappa x) \sin (\kappa x)+C_{4} \cosh (\kappa x) \cos (\kappa x)
\end{aligned}
$$

At the point of load introduction at midspan $(\mathrm{x}=0)$ where the maximum indentation occurs, equation (9) reduces to its coefficient $C_{4}$ given in equation (9) for the considered boundary conditions (face sheet considered as a beam simply supported at both ends with a point force applied at midspan) with $\kappa$ as defined in equation (10).

$$
\begin{aligned}
C_{4} & =-\frac{P}{8 \kappa^{3} D_{f}} \\
\kappa^{4} & =\frac{K_{z}}{4 D_{f}}
\end{aligned}
$$

The elastic reaction stress $q_{z}$ of the foundation at the core/top face sheet interface can then be expressed analogue to a linear tension/compression spring:

$$
q_{z}(x)=-K_{z} w_{\text {local }}(x)
$$

By equating equation (9) and (11) and by rearanging the equation for $P$, followed by replacing the interfacial normal stress $q_{z}$ with the compressive core stength $X_{c}$ and after multiplying the RHS with width $b$, the critical load to cause core crusing failure $P_{\text {crit }}$ is obtained for a sandwich beam:

$$
P_{\text {crit }}=\frac{8 b X_{c} D_{f}}{K_{z}}\left(\frac{K_{z}}{4 D_{f}}\right)^{\frac{3}{4}}
$$

The model implicitly assumes that the through-thickness core stresses induced by the localized bending (indentation) of the top face sheet decay completely through the thickness of the core, and accordingly that the behaviour of the bottom face sheet is still fully described by classical sandwich beam theory only (i.e. no local interaction between top and bottom face sheets). The analytical model is restricted to predict stresses and displacements in the top face sheet to core interface, and the top face sheet is assumed to behave as a laminated beam that is incompressible in the through-thickness direction. 


\section{Experimental investigation}

The three-point bending experiments conducted on sandwich beams subjected to elevated temperature were carried out on an Instron 8502 servo-hydraulic test machine equipped with a $50 \mathrm{kN}$ load cell. The sandwich beam was supported by two steel rollers with a diameter of $22.5 \mathrm{~mm}$ and indented by a $15 \mathrm{~mm}$ diameter roller. The side supports were moved upwards by the hydraulic test machine and the midspan indenter was stationary. This is the opposite to the modelling adopted in some of the FE and analytical models. The experimental results were treated accordingly for later comparisons. An infrared lamp was suspended from the test machine crosshead and pointed at the top face sheet of the test specimen. The strainsmart 6200 system was used to record the load, the crosshead displacement and six thermocouple readings to monitor the through-thickness temperature gradient. Figure 6 shows the experimental setup used for the testing of foam cored sandwich beam specimens in threepoint bending and simultaneous thermal loading.

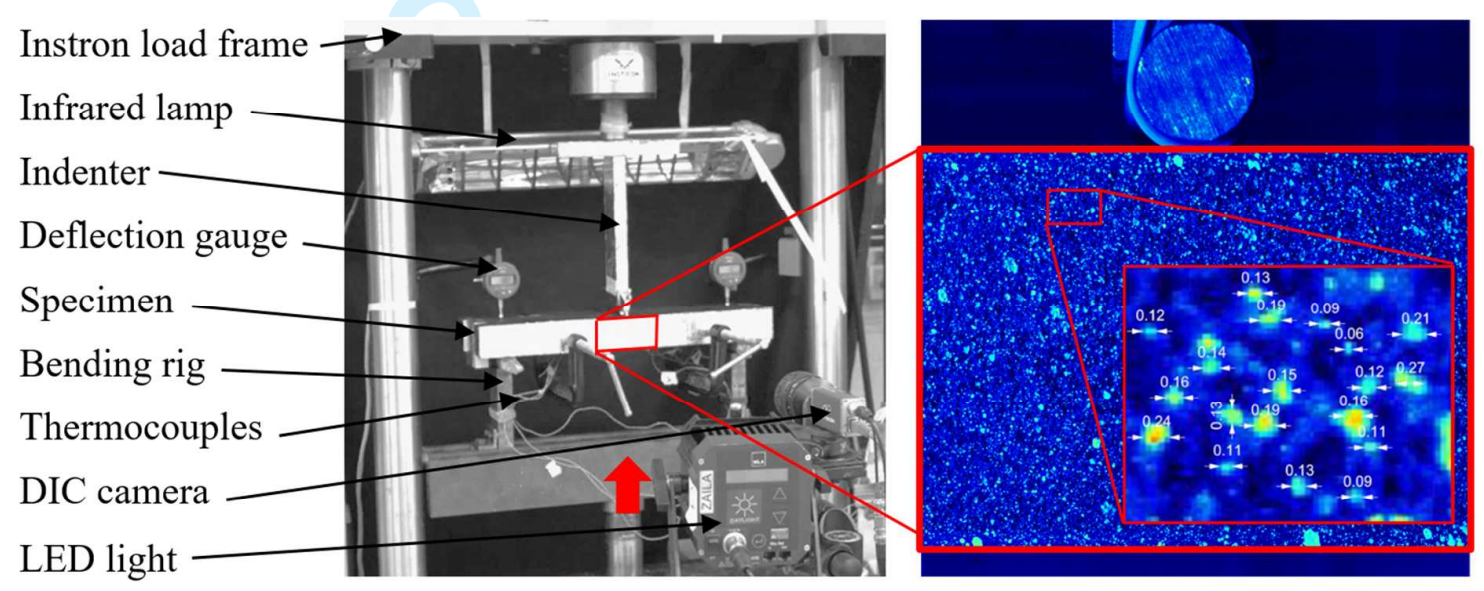

Figure 6. Three-point bending experimental set-up (left), and the region of interest (ROI) as seen through the DIC camera with a detailed view of the speckle pattern (right).

Before the load was applied, the infrared lamp was switched on while the side surfaces of the sandwich beam were covered with PVC insulation panels. Six thermocouples were used to monitor the developing temperature profiles. Figure 7 shows the positions of the thermocouples relative to midspan and the average temperature profiles obtained for the investigated temperature cases. The spatial distribution of the thermocouples (column at the centreline (CL) and column at the front surface) allowed to check for any undesired widthwise variations of the temperature. The achieved through-thickness temperature profiles were close to linear and therefore in accordance with the heat conduction equation [19]. Conductive heat transfer, seeking a thermal equilibrium condition, takes place in a medium (here PVC foam core) that is subject to a temperature gradient. The governing equation states, that the equilibrium temperature at any given point in the medium is linearly proportional to its through-thickness location. The slight nonlinear temperature distribution, especially for the $T t$ $=90^{\circ} \mathrm{C}$ case, can be attributed to the relatively large side surfaces of the thick and narrow beam which leads to rapid heat loss and a decay of the perfect linear temperature profiles once the insulation panels are removed and the experiment was started. In addition to the thermocouples embedded in the foam core, the front surface temperature of the core was monitored with an infrared camera [14]. 

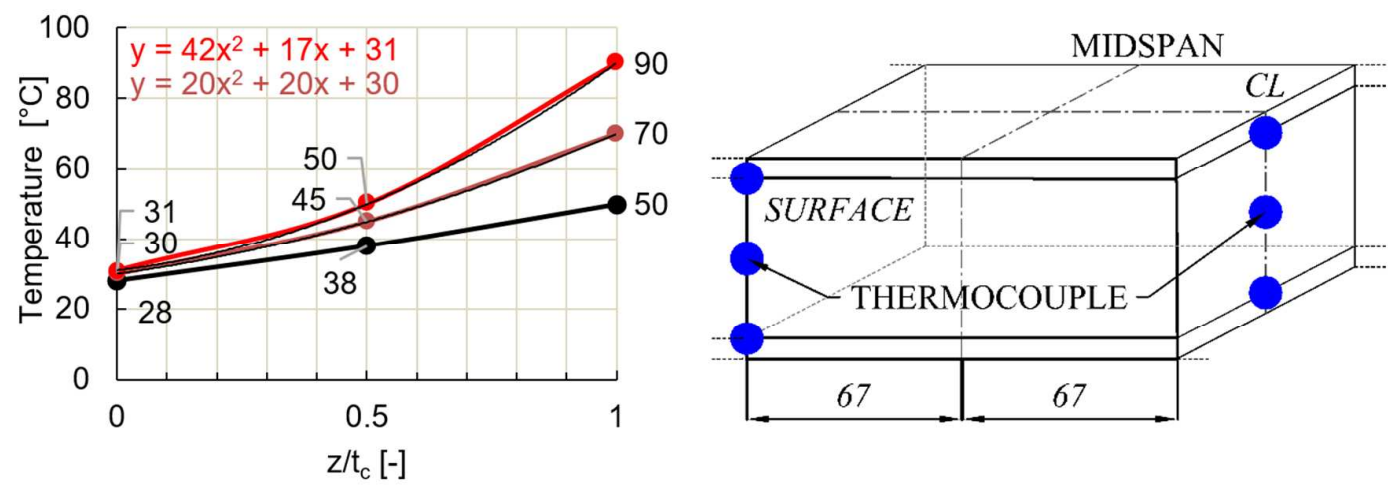

Figure 7. Average temperature profiles established with six thermocouple readings through the core (left), and the positions of the thermocouples relative to midspan (right).

The mechanical tests were carried out in manual position control mode of the test machine. This means that the lower bending rig support was stepwise moved upwards until the required load steps were reached. The beam was loaded incrementally in load steps of $500 \mathrm{~N}$. The maximum load was $5000 \mathrm{~N}$ at $25^{\circ} \mathrm{C}$ and $1500 \mathrm{~N}$ at $90{ }^{\circ} \mathrm{C}$, indicating the significant reduction of the load carrying capability at elevated temperatures. Three specimens were loaded at each temperature case within their elastic limits and one of each was further loaded up to failure. The digital image acquisition camera LaVision Imager E-Lite 5M equipped with a AF NIKKOR $50 \mathrm{~mm}$ lens was positioned approximately $600 \mathrm{~mm}$ away from the specimen front surface focusing on the mid-span indentation region. Care was taken to align the camera perpendicular to the specimen surface. The ROI, $+/-35 \mathrm{~mm}$ to each side of midspan, was spray painted matt black before white spray painted speckles were applied. Two LED lights were focused on the ROI to improve the contrast of the speckle pattern. The commercially available DIC software DaVis 8.1.4 from LaVision was used to correlate the obtained images with a subset size of $81 \times 81$ pixels, a step size of $25 \%$ and a $6^{\text {th }}$ order spline interpolant. Strains were derived after a $3 \times 3$ Kernel Gaussian smoothing filter was applied to the displacement fields [20]. The measured displacement and strain fields were post-processed in MATLAB and visualized as shown in Figure 8. A surface was laid through the obtained point cloud using a MATLAB in-built linear interpolation fit. Any free body upward movement of the beam at the first load step due to a small gap between beam and indenter was subsequently corrected numerically. A coordinate transformation was performed to move the origin of the graph to the point of indentation. Finally, through-thickness displacement and strain profiles were extracted from the master surfaces at $\mathrm{x}=0$. 
a)
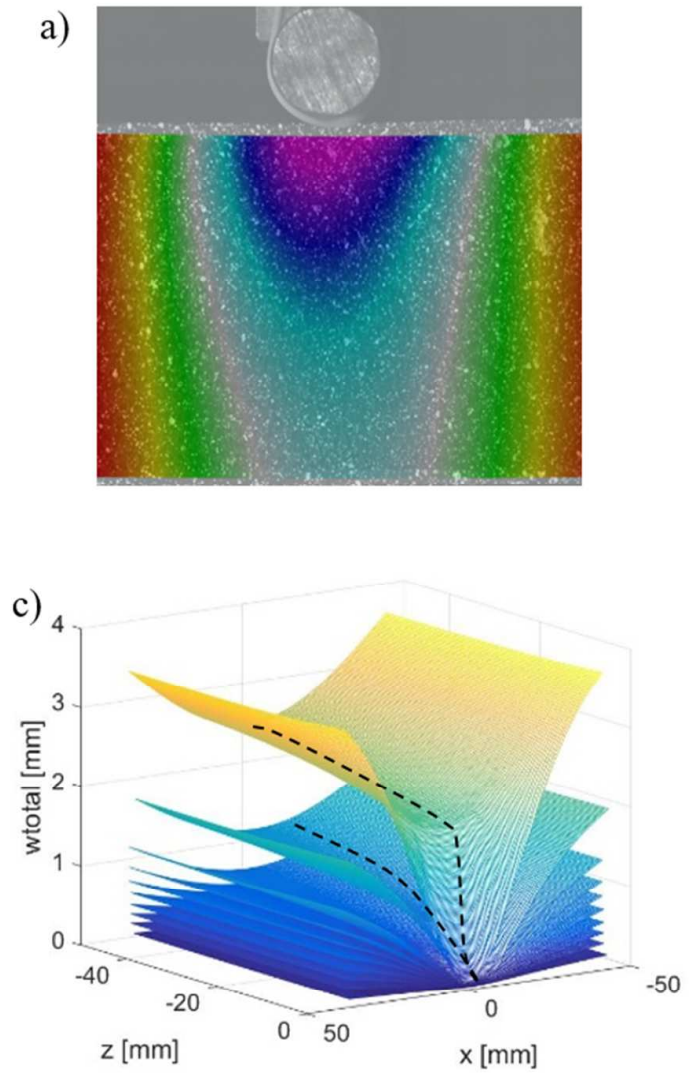

b)

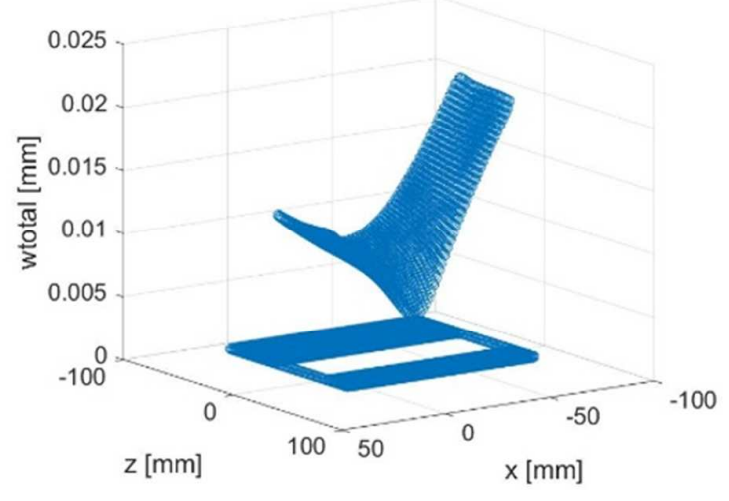

d)

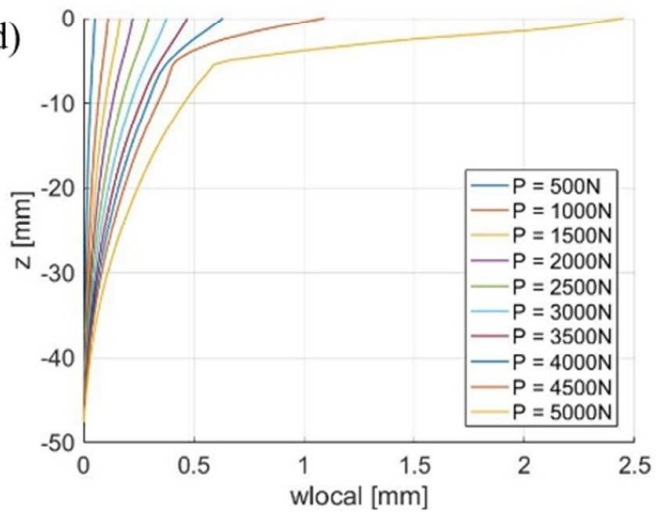

Figure 8. Post-processing in MATLAB: a) DIC displacement field in DaVis, b) imported DIC data cloud for single load step, c) generated master surfaces reduced to the ROI for all load steps, $\mathrm{d})$ extracted through-thickness displacement profiles at midspan $(\mathrm{x}=0)$.

\section{Finite Element Modelling (FEM)}

The FE analyses were conducted using the commercial software ANSYS APDL 17.0. A 2D plane stress model was constructed with PLANE82 8-Node quadratic structural elements as shown in Figure 9.

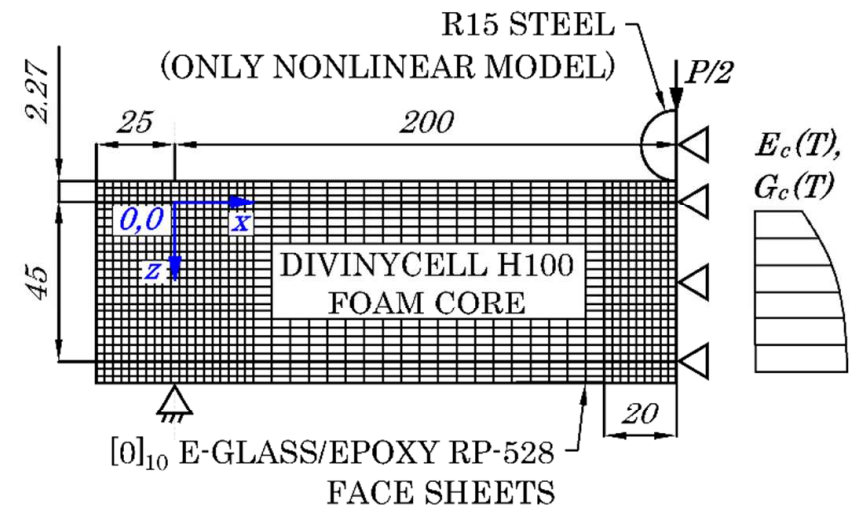

Figure 9: FE model with boundary conditions, mesh features, dimensions and degraded foam core material properties. 
Due to symmetry of the sandwich beam in three-point bending, a half model was adopted and a symmetry boundary condition was applied at midspan. The node at the bending rig support point was restricted in the $z$ (through-thickness) direction, and a point force of $\mathrm{P} / 2$ was applied at midspan directly at the top face sheet for the simple linear model, or at the modelled indenter for the nonlinear contact model. To account for the temperature dependent core material properties, the core was vertically divided into a finite number of slices. The temperature in the centre of each horizontal slice was computed based on the input of the top face sheet temperature $T_{t}$ and the bottom face sheet temperature $T_{b}$, assuming a linear throughthickness temperature gradient. The temperature degraded properties of each slice were than computed based on the proposed regression formula in equation (1). Displacement compatibility between skins and core was imposed through 'gluing' the different areas together. The adhesive layer separating the face sheets and the core (SA80 film adhesive) was assumed to be very thin and was ignored. The FE mesh featured longitudinal refinement areas at the point of load introduction at midspan and at the side supports.

Two mesh convergence studies, one at room temperatures and one at elevated temperatures, were conducted. It was found, that a high number of constant temperature slices through the core thickness is crucial for an accurate prediction of the through-thickness strains and stresses in the critical area of the core near the indenter due to the large change of the temperature reduced foam core properties near the top face sheet. The final mesh featured eight elements through the face sheet thickness and 40 constant temperature core slices, each with four elements in the through-thickness direction. Longitudinally, the elements were 1 $\mathrm{mm}$ long in the crude and $0.5 \mathrm{~mm}$ long in the refined meshing areas.

Initially, a linear elastic material model was assumed and a point force was directly applied at the top face sheet, ignoring the contact problem between indenter and sandwich beam. It quickly became apparent that the core material exhibits a strongly nonlinear behaviour even before reaching core crushing stress levels. Naturally, for polymer materials, nonlinear effects became even more pronounced at higher temperatures. This led to the development of a second and nonlinear FE model that included the nonlinear contact problem between indenter and sandwich beam, geometric nonlinearity (expected in the top face sheet close to the indenter), and most importantly a nonlinear material model for the foam core. The polymer foam material will also display visco-elastic effects that can be expected to increase with temperature, especially at temperatures approaching or above $T_{g}$. However, visco-elastic effects were not included in the modelling conducted. Hill's generalized anisotropic plasticity model was adopted as proposed in [8]. The technical details of the material model can be found in the ANSYS documentation [21]. The model accounts for different compressive and tensile yield strengths $\left(\sigma_{i}, \sigma_{c i}\right)$ and shear strength $\tau_{i}$ as well as different stiffnesses before (standard elastic moduli $E_{0 i}$ and $G_{0 i}$ ) and after the yield point (tangent moduli $E_{T i}$ and $G_{T i}$ ) in all three material axes $(i=x, y, z)$. The parameters must satisfy certain constraining relationships, which are outlined in the ANSYS documentation. The most limiting one is the incompressibility requirement:

$$
\frac{\sigma_{x}-\sigma_{x c}}{\sigma_{x} \sigma_{x c}}+\frac{\sigma_{y}-\sigma_{y c}}{\sigma_{y} \sigma_{y c}}+\frac{\sigma_{z}-\sigma_{z c}}{\sigma_{z} \sigma_{z c}}=0
$$

The incompressibility requirement implies that plastic yielding is assumed to be the result of deviatoric stresses alone, whereas dilatational (hydrostatic) stresses do not play a role. This is a questionable assumption for cellular polymer core materials like Divinycell H100 used in this work. However, Hill's anisotropic yield hypothesis, as implemented in ANSYS, has been 
used for this work none the less, and it is assessed that the most important effects of material plasticity will be captured with sufficient accuracy for the purposes of this research. To determine all the required material parameters correctly, a range of test data would be required. However, as the tested sandwich specimen is designed to fail due to throughthickness (z-axis) core crushing, only the through-thickness compressive nonlinear yield behaviour is assumed to be relevant. Accordingly, the stresses in the other material axes are assumed never to exceed their respective yield strengths. This means that no accurate determination of these parameters is required, for as long as the material will yield in throughthickness compression before any other yield point is reached. With the adoption of these assumptions, it is relatively straightforward to fulfil equation 13, simply by starting to define the important through-thickness compressive yield strength and tangent moduli first. The tensile value of the corresponding material axis is then set to the same value as the compressive value to ensure the fulfilment of the incompressibility requirement. Tensile and compressive parameters in the remaining material axes ( $x$ and $y$ ) are set according to the tensile properties derived in [2-8]. An overview of the nonlinear material model input is given in Table 3.

Table 3. Material properties used for Hill's plasticity model in ANSYS at room temperature $\left(25^{\circ} \mathrm{C}\right)$.

\begin{tabular}{llll}
\hline Material Property $/ \mathrm{i}=$ & $\mathrm{x}$ (longitudinal) & $\mathrm{z}$ (through-thickness) & $\mathrm{y}$ (width direction) \\
\hline $\mathrm{E}_{0 \mathrm{i}}[\mathrm{MPa}]$ & 58 & $115.5^{1}$ & 58 \\
$\sigma_{\mathrm{i}}[\mathrm{MPa}]$ & 0.9 & 1.73 & 0.9 \\
$\mathrm{E}_{\mathrm{Ti}}[\mathrm{MPa}]$ & 6.66 & 25.61 & 6.66 \\
$\sigma_{\mathrm{ci}}[\mathrm{MPa}]$ & 0.9 & 1.73 & 0.9 \\
$\mathrm{E}_{\mathrm{Tci}}[\mathrm{MPa}]$ & 6.66 & 25.61 & 6.66 \\
$\tau_{\mathrm{i}}[\mathrm{MPa}]$ & 1.44 & 1.44 & 1.44 \\
$\mathrm{G}_{\mathrm{Ti}}[\mathrm{MPa}]$ & 3.33 & 3.33 & 3.33 \\
\hline${ }^{1}$ Slightly reduced from standard literature value to improve bilinear material model fit.
\end{tabular}

The important compressive through-thickness properties were obtained from stress-strain curves derived in [5]. Figure 10 shows the real and the assumed linear and bilinear stressstrain curves. The stiffness change after the defined yield point is sufficient to capture the material behaviour within its elastic region. After the collapse strain of 0.02 was reached no further analyses into the post core crushing domain were conducted. The predictions obtained with the nonlinear FE model are sensitive to the selected through-thickness parameters and they could easily be tuned/calibrated to further improve the fit with experimental data. However, this was considered to be beyond the scope of this research. 


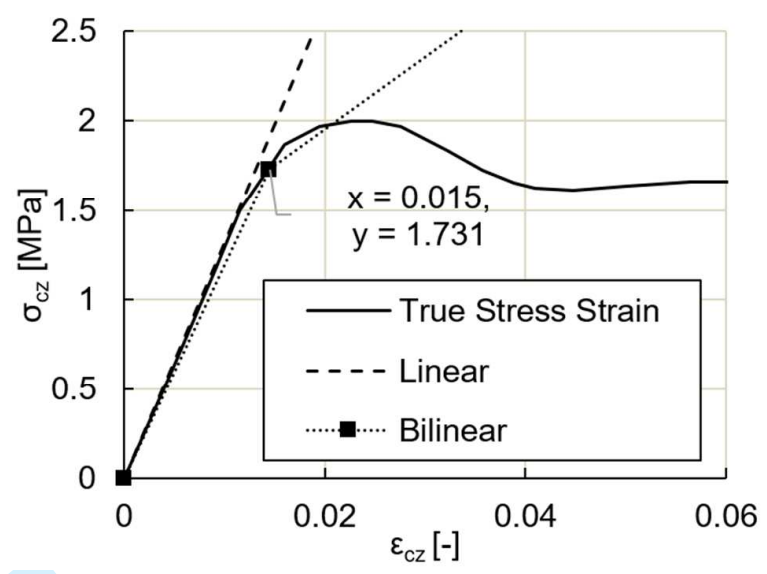

Figure 10. True transverse compressive stress-strain curve and the linear and bilinear material models for the H100 PVC foam.

For the elevated temperature cases all material properties listed in Table 3 for room temperature, were scaled down according to equation (14) in proportion to the degraded/reduced standard Young's modulus.

$$
\sigma_{i}\left(X^{o} C\right)=\frac{E_{0 i}\left(X^{o} C\right)}{E_{0 i}\left(25^{o} C\right)} \sigma_{i}\left(25^{o} C\right)
$$

\section{Comparative Assessment and Synthesis of Results}

In this section, the analytical and FEM predictions are compared against the experimental measurements to assess their predictive capability. Recall that the experimental data consists of displacement and strain fields only, and that no stress information was obtained. The analytical model predicts the local (top face sheet) deflections and interfacial normal stresses at the top face sheet to core interface, whereas no full field stress and strain data is available. However, both full field stress and strain data have been obtained by the linear and nonlinear FE analyses.

Figure 11 compares the experimentally obtained local displacement fields with the nonlinear FE predictions. The agreement for all temperature cases apart from the $90{ }^{\circ} \mathrm{C}$ case is good as the similarity of the displacement contours shows.
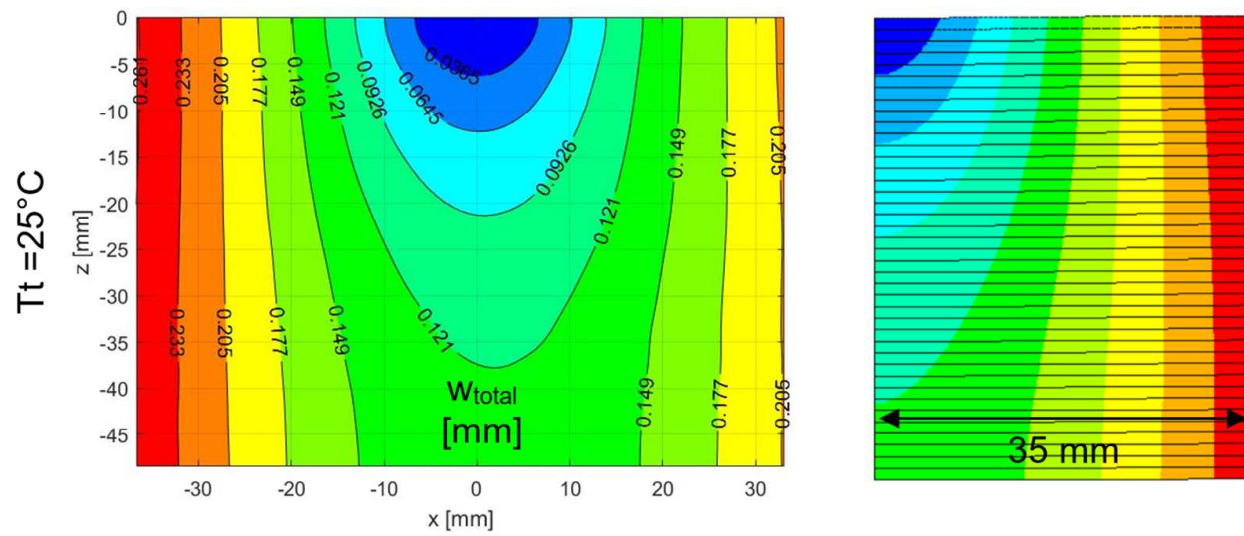

ANSYS Release 17. Build 17.0 SEP 20201

$\begin{aligned} 11: 14: & 19 \\ & .836 \mathrm{E}-05\end{aligned}$ $.365 \mathrm{E}-04$
$.645 \mathrm{E}-04$ $.645 \mathrm{E}-04$
$.926 \mathrm{E}-04$ $\square \quad .121 \mathrm{E}-03$ $.149 \mathrm{E}-03$ $.177 \mathrm{E}-03$
$.205 \mathrm{E}-03$ $.233 \mathrm{E}-03$ $\mathrm{W}_{\text {total }}[\mathrm{m}]$ 

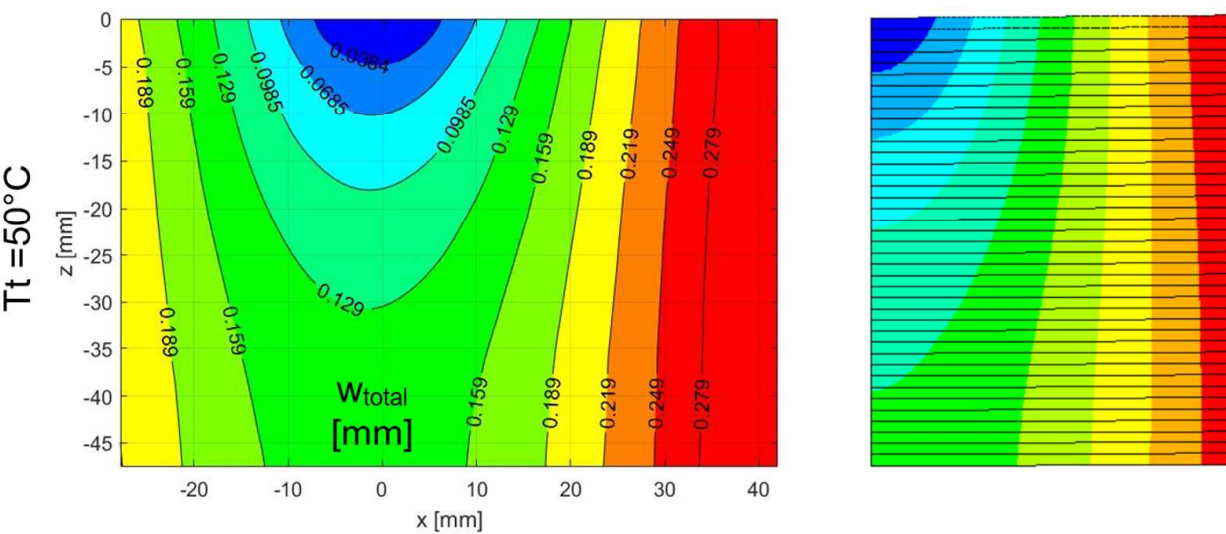

ANSYS Release 17.0

Build 17.0

SEP 202016

$11: 30: 37$

$.836 \mathrm{E}-05$
$.384 \mathrm{E}-04$
$.685 \mathrm{E}-04$

$.985 \mathrm{E}-04$

$129 \mathrm{E}-03$
$159 \mathrm{E}-03$

$159 \mathrm{E}-03$
$189 \mathrm{E}-03$

.219E-03

$.249 \mathrm{E}-03$

$\mathrm{W}_{\text {total }}[\mathrm{m}]$
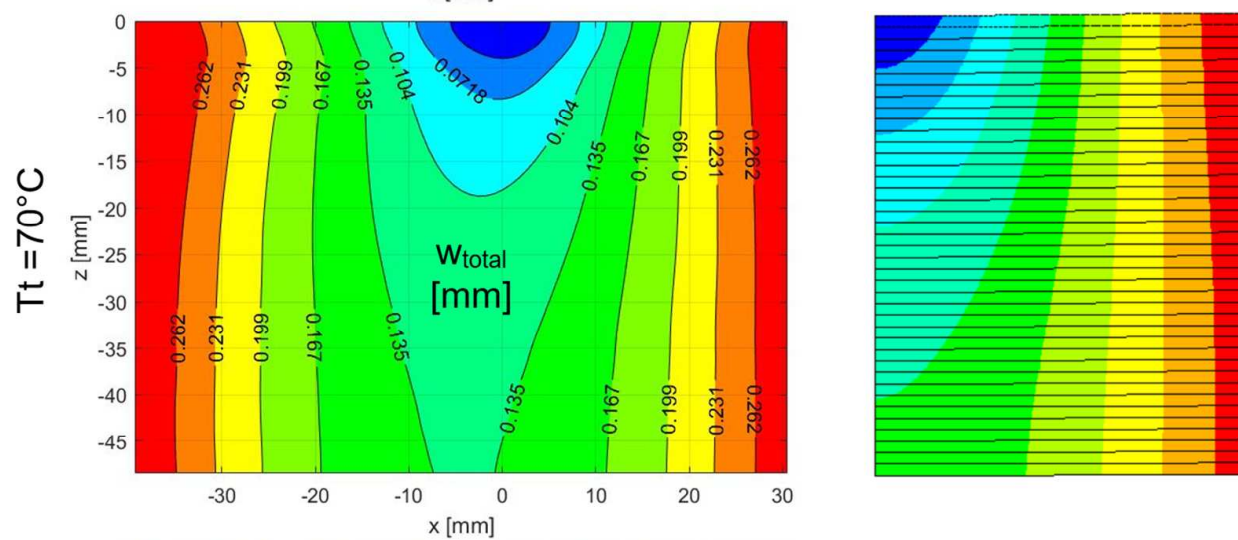

ANSYS Release 17.0 Build 17.0 SEP 202016 $11: 41: 26$

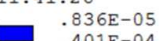

$.401 \mathrm{E}-04$

$.718 \mathrm{E}-04$
$.104 \mathrm{E}-03$

$.135 \mathrm{E}-03$
$.167 \mathrm{E}-03$

$.167 \mathrm{E}-03$
$.199 \mathrm{E}-03$

$.231 \mathrm{E}-03$
$.262 \mathrm{E}-03$ $.294 \mathrm{E}-03$

$\mathrm{W}_{\text {total }}[\mathrm{m}]$
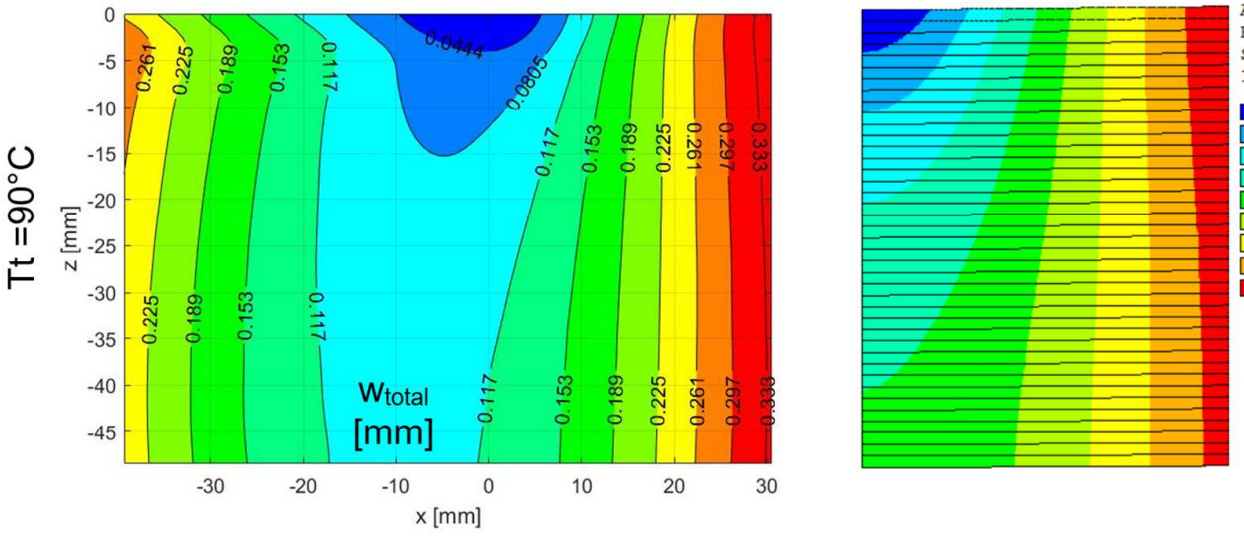

ANSYS Release 17.0 Build 17.0 $11: 50: 18$

$.836 \mathrm{E}-05$
$.444 \mathrm{E}-04$ $.805 E-04$ $.117 \mathrm{E}-03$ $153 \mathrm{E}-03$ $.225 \mathrm{E}-03$ $.261 \mathrm{E}-03$ $.261 \mathrm{E}-03$ $.333 \mathrm{E}-0$

$\mathrm{w}_{\text {total }}[\mathrm{m}]$

Figure 11. Experimental (left) and nonlinear FE results (right) - local deflection fields at $\mathrm{P}=$ $1000 \mathrm{~N}$ for all temperature cases; $\mathrm{T}_{\mathrm{t}}=25,50,70$ and $90{ }^{\circ} \mathrm{C}$.

Figure 12 compares predicted and the experimentally obtained through-thickness displacement profiles at beam midspan for all investigated temperature cases at $\mathrm{P}=500,1000$ and $1500 \mathrm{~N}$. The local deflection at midspan is important, because the maximum indentation and hence core crushing failure initiates at midspan just below the core to top face sheet interface $(\mathrm{z}=0)$. Moreover, the profiles illustrate the nature of the through-thickness local displacement decay. 

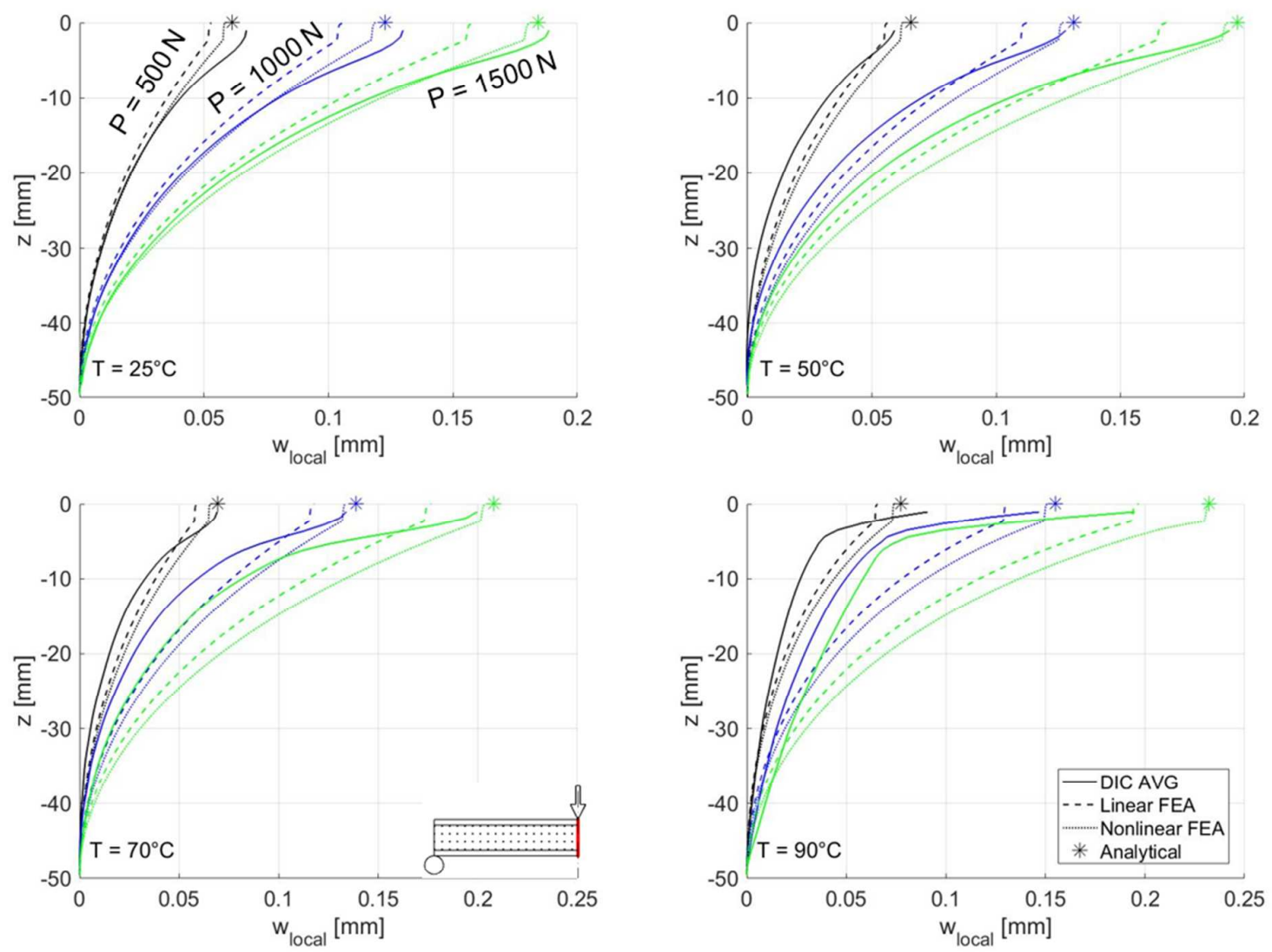

Figure 12. Through-thickness local face sheet deflection profiles at $\mathrm{P}=500$ (black), 1000 (blue) and $1500 \mathrm{~N}$ (green) for different temperature cases.

By comparing the local displacement fields and through-thickness profiles at midspan, the following conclusions can be drawn regarding the predictive capability of the FE and analytical models:

- Generally, the predicted maximum indentation at the top face sheet $(z=0)$ from both FE models (dotted and dashed lines) and analytical model (star) correspond well with the experimental data (full lines) for all shown load cases and up to $70^{\circ} \mathrm{C}$.

- At an applied top face sheet temperature $T_{t}=90^{\circ} \mathrm{C}$ the glass transition temperatures of the SA80 adhesive film (Max $T_{g}=99^{\circ} \mathrm{C}$ at a cure temperature of $120^{\circ} \mathrm{C}$ ) and of the $\mathrm{H} 100$ foam core $\left(T_{g}=85^{\circ} \mathrm{C}\right)$ is approached or exceeded and face sheet debonding led to identical premature failure for two of the investigated specimens. Thus, indentation failure at $90{ }^{\circ} \mathrm{C}$ was not observed experimentally and the recorded displacement and strain maps cannot be compared against model predictions, which do not include this highly nonlinear effects.

- The analytical results indicate that the proposed temperature dependent foundation modulus $K_{z}$ is a good choice to calculate the local displacements for the investigated sandwich beam at elevated temperatures. Using the average through-thickness compressive Young's modulus $E_{c}^{A V G}$ to compute the foundation stiffness yields satisfactory predictions of the local deflections at elevated temperatures.

- The nonlinear FE model predicts the through-thickness local deflection fields and profiles in close agreement with the experimental data for the two lower temperature test cases and reasonably well for the $70^{\circ} \mathrm{C}$ case. The nonlinear FE predictions are consistently 
more accurate than the linear model predictions, and the predicted maximum indentation values are higher and in better agreement with measurements.

Figure 13 compares the through-thickness strain profiles at midspan obtained experimentally and by means of the FE models. The following conclusions can be drawn:

- The local though-thickness strain profiles show that the through-thickness decay of the local normal strain for the investigated specimen is complete, which is confirmed by both the experimental data and the FE models. This validates the fundamental assumption behind the proposed analytical model of a complete through-thickness decay of the core normal stresses and strains.

- The measured local through-thickness strain profiles appear to be parabolic, which is typical for elastic foundation problems [21]. The nonlinear FE model is capable of predicting the parabolic decay as shown clearly for the $\mathrm{Tt}=90^{\circ} \mathrm{C}$ case, whereas the linear FE model predicts quasi linear local strain profiles. By fine tuning the crudely defined plasticity parameters of the nonlinear FE model, the onset of nonlinearity could be shifted to a lower stress or temperature level, and the strain profiles would become more parabolic already at the lower temperature cases which would improve the fit with the experimental data. This was not attempted, as the purpose of the modelling was to capture the overall features of the load response as well as the peak indentation values.

- The experimental data generally shows higher maximum strain values than predicted by the FE models. However, the nonlinear FE model predictions again could have been improved by fine tuning Hill's anisotropic material model. 

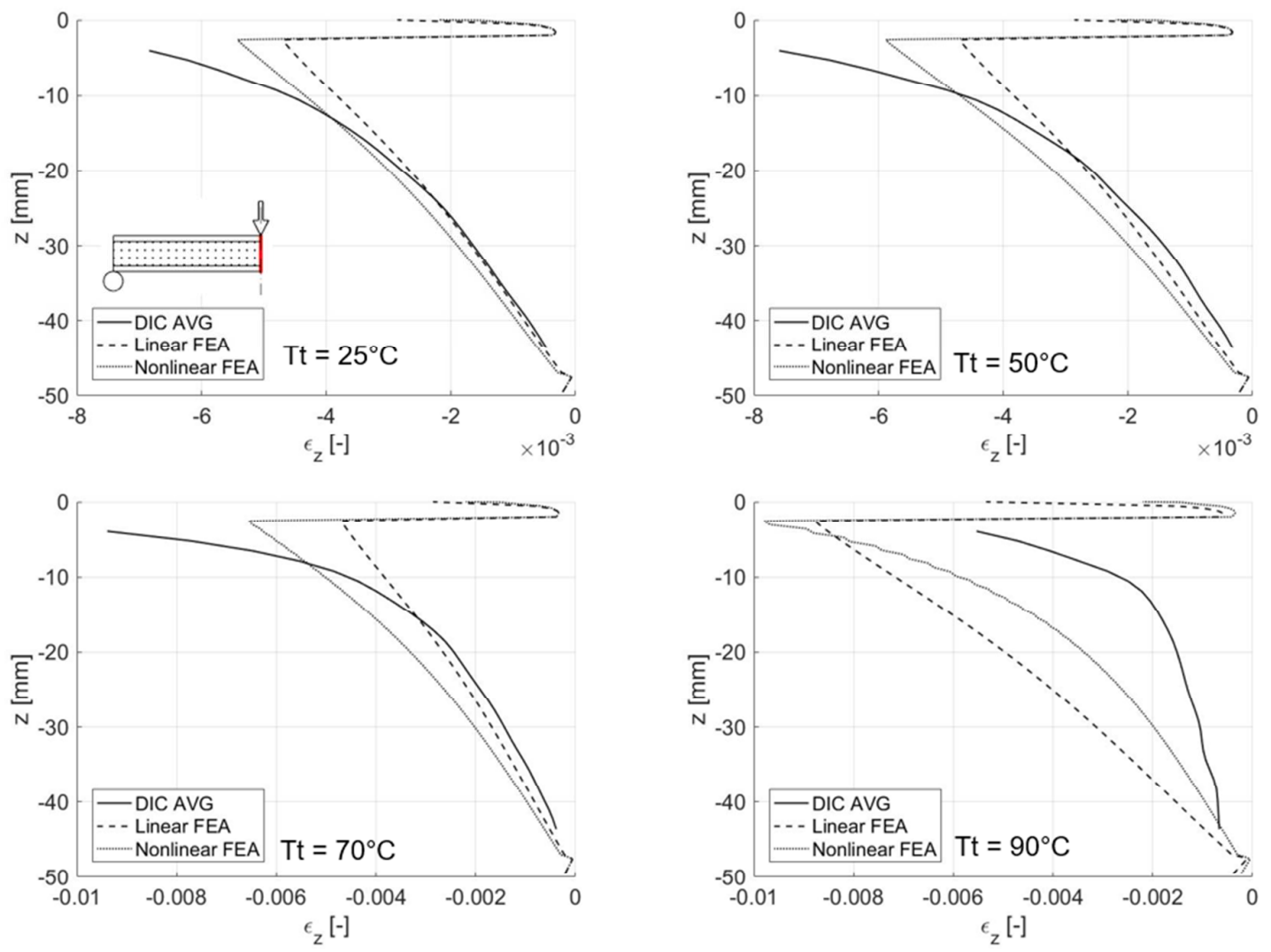

Figure 13. Through-thickness transverse strain profiles at midspan at $\mathrm{P}=1000 \mathrm{~N}$ for different temperature cases.

Figure 14 compares interfacial normal stresses $q_{z}$ along the top face sheet to core interface for $T_{t}=25^{\circ} \mathrm{C}$ and $90{ }^{\circ} \mathrm{C}$ at load $P=1000 \mathrm{~N}$ and $2500 \mathrm{~N}$ predicted with the analytical and $\mathrm{FE}$ models. All models predict a very similar longitudinal stress distributions along the top face sheet to core interface. However, the maximum interfacial normal stress at midspan is approximately $15 \%$ lower for the analytical prediction in comparison to the FE predictions at room temperature. This means that failure prediction based on the analytical model is nonconservative when compared to the FE predictions. Both FE models predict identical stresses for the $P=1000 / T_{t}=25{ }^{\circ} \mathrm{C}$ case while discrepancies increase slightly for the cases with higher load and/or temperature. Generally, all models predict reduced stresses and show better agreement at elevated temperatures than at room temperature. 


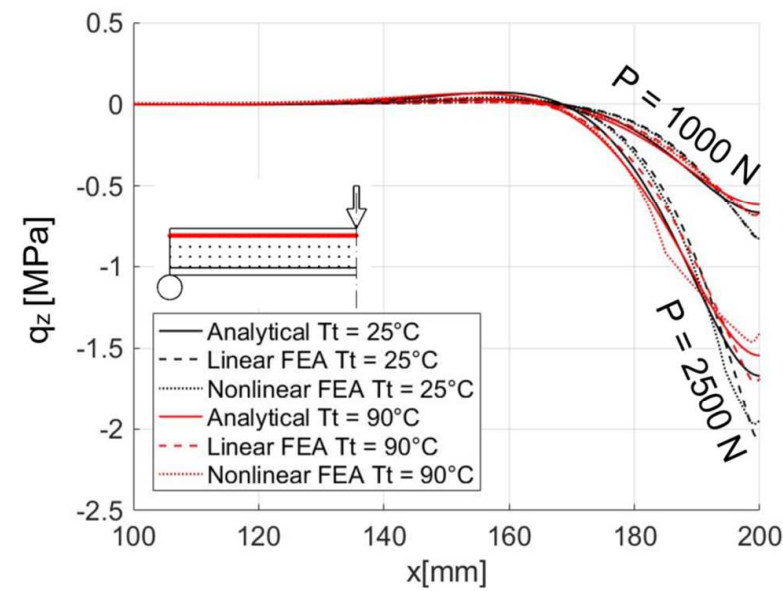

Figure 14. Interfacial normal stress distributions - analytical model vs. FE models

In summary, it has been demonstrated that the FE models are capable of predicting local deflections and strains that agree with the experimental data for the three lower temperature cases, i.e. 25,50 and $70{ }^{\circ} \mathrm{C}$. The analytical model predicts interfacial normal stresses that correspond reasonably well with both the linear and nonlinear FE results, hence it is possible to estimate the core crushing failure loads for the investigated sandwich beam reasonably accurate using the analytical model as well as by means of the FE models. Figure 15 shows the predicted and experimentally recorded foam core crushing loads based on the computed stresses or strains and the material strengths or failure strains as a function of temperature. Because no major interaction between the global and local bending response of the investigated foam cored sandwich beam was detected, the critical core crushing failure load can easily be estimated analytically by equation (12).

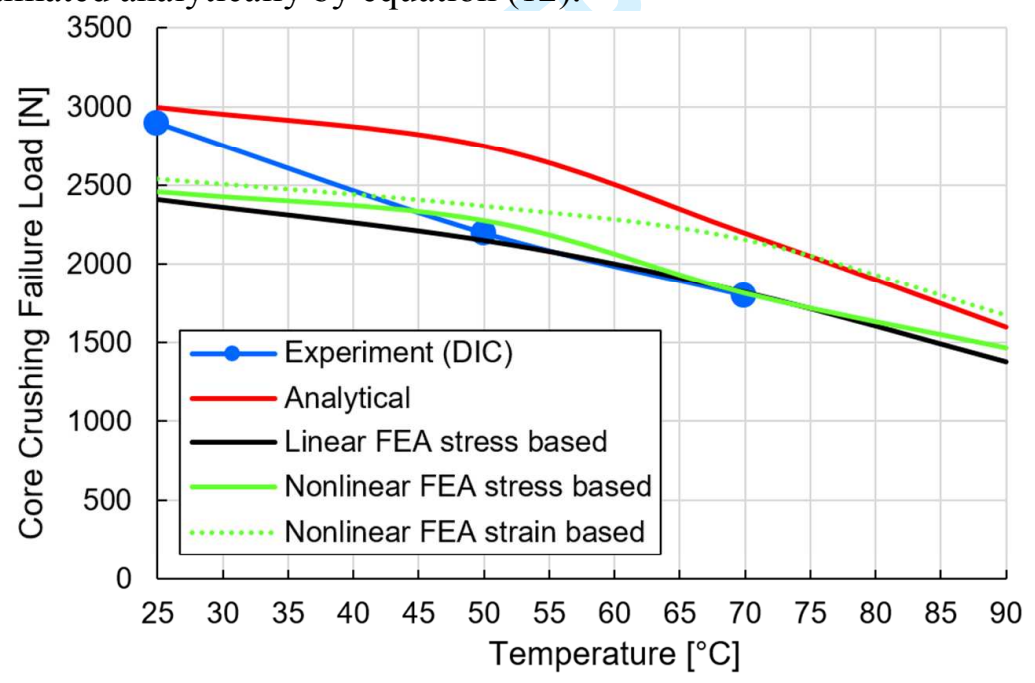

Figure 15. Core crushing failure load vs. temperature measured experimentally and predicted by means of the analytical and FE models.

Referring to Figure 15, the experimentally determined core crushing failure load is defined as the load where the maximum trough-thickness normal strain in the core equals the strain to failure as a function of temperature. In the analytical model, failure has occurred when the maximum interfacial normal stress exceeds the through-thickness compressive strength of the foam core. As for the FE analyses, failure can be defined either based on the predicted stress 
or strain. However, failure predicted based on strain is considered representative only for the nonlinear FE model predictions. With respect to the linear FE model, the discrepancy between the true and assumed linear stress-strain curve is too large to be able to determine failure based on a strain criterion, and doing so would result in a significant over-prediction of the critical core crushing load.

Figure 15 shows that the critical core crushing failure load reduces significantly at elevated temperatures for the considered foam cored sandwich beam specimen. The core crushing failure load reduced by about $30 \%$ at $70{ }^{\circ} \mathrm{C}$ and by about $50 \%$ at an elevated temperature of $90{ }^{\circ} \mathrm{C}$ relative to the ambient temperature case. The reduction is mainly driven by the decreased strength or crushing strain of the foam core at elevated temperature.

The analytical model overestimates the core crushing failure loads by about $20 \%$, which is not surprising when considering Figure 14, which showed that the analytical model predicts lower interfacial normal stresses than both FE models.

Regarding the FE models, the results presented suggest that both the linear and nonlinear models are able to predict the critical core crushing failure load with reasonable accuracy based on the stress failure criterion, but only the nonlinear model can also predict failure based on the strain failure criterion.

It must be noted, that the research presented does not supply sufficient evidence to conclude that the general trend in accuracy of the predictions would be similar for different sandwich beam configurations with e.g. different core thicknesses and core stiffness.

\section{Conclusion}

In this paper, a foam cored sandwich beam with laminated GFRP face sheets subjected to a through-thickness temperature gradient was studied experimentally, analytically, and by means of linear and nonlinear FE models. The aim was to evaluate how the temperature reduced foam core properties will affect the local deflections, core stresses, and the critical indentation failure load, and hence the structural integrity of a foam cored sandwich structure exposed to elevated temperatures. This allowed defining guidelines for design and validating a simple analytical design tool to avoid premature indentation failure at elevated temperatures. The study has clearly shown, that the critical core crushing failure load reduces significantly with elevated temperatures. At a top face sheet temperature of $70^{\circ} \mathrm{C}$ the critical indentation failure load was reduced by approximately $30 \%$, and at a top face sheet temperature of $90{ }^{\circ} \mathrm{C}$ by $50 \%$. The reduction of load carrying capability is mainly driven by the decrease of the core compressive or crushing strength, which outweighs the decrease of compressive stresses in the core due to material softening at elevated temperatures.

Based on experimental evidence and underpinned by FE results, a simple, approximate analytical model is proposed that can predict the local core stresses and deflections at elevated temperatures. The model is an extension of an existing model framework developed to predict the local response of a sandwich beam at room temperature. It was found, that especially the predicted local deflections of the top face sheet are in excellent agreement with FE predictions and experimental measurements for all investigated temperature cases. The analytically predicted longitudinal distribution of core stresses, best characterized by the wave length of the stress distribution, was found to be in good agreement with FE predictions for all temperature cases as well. The analytically predicted maximum core stress at midspan was found to be approximately $15 \%$ lower than predicted by the FE models for this particular beam, which leads to a non-conservative analytical prediction of the critical core crushing failure load. It has been shown that the proposed analytical model is able to predict core crushing failure at elevated temperatures, and with a similar degree of accuracy as observed at 
room temperature. This shows that averaging the reduced through-thickness compressive | Young's moduli to calculate the foundation modulus is a simple and efficient way to estimate indentation failure at elevated temperatures. The major discrepancy between the predictions of the analytical model, the experimental data and the FE models does not arise from the implemented temperature dependency of the core stiffness properties, but can be attributed to the dependency of the foundation modulus $K_{z}$ on the sandwich beam geometry and material parameters, regardless of the applied temperature gradient. To improve the accuracy of the analytical model, more sophisticated elastic foundation models would have to be considered. This is considered feasible, but lies beyond the scope of this research.

Regarding the developed FE models, it was found that both the linear and nonlinear models are able to predict indentation failure based on a stress failure criterion. However, only the nonlinear FE model is able to predict local displacements and strains at elevated temperatures accurately and in good agreement with the experimental measurements. Moreover, the nonlinear FE model was able to capture the expected nonlinear (parabolic) decay of the strains through the core thickness. For the investigated foam cored sandwich beam configuration, both FE model predictions and the experimental data suggested a complete decay of the localized effects through the core thickness for all temperature cases. This means, that the global and local bending response can be superimposed, and that no interactions between the face sheets are to be expected. This justifies the fundamental restrictive assumption adopted for the approximate analytical models that was investigated in this research. Accordingly, the adoption of the simple analytical model frame work, which is based on the assumption that the loaded face sheet can be considered as supported by an elastic foundation, has been validated at elevated temperatures for the investigated sandwich beam.

\section{Acknowledgements}

The H100 grade PVC foam core material used for the tests presented in this study was generously provided by DIAB Group, Laholm, Sweden. The support received is gratefully acknowledged.

\section{Conflict of Interest}

None declared.

\section{Funding}

The authors received no financial support for the research, authorship, and/or publication of this article.

\section{References}

1. Zenkert D. An introduction to sandwich structures. Student ed. Stockholm, 2005.

2. Zhang S, Dulieu-Barton JM, Fruehmann RK, Thomsen OT. A methodology for obtaining material properties of polymeric foam at elevated temperatures. Exp Mech 2012; 52: 3-

15. 
3. DIAB. Divinycell PVC datasheet. http://www.diabgroup. com (accessed September 2016).

4. Taher ST, Thomsen OT, Dulieu-Barton JM, Zhang S. Determination of mechanical properties of PVC foam using a modified Arcan fixture. Comp Part A 2012; 43(10): $1698-708$

5. Taher ST, Thomsen OT. Compressive behaviour of PVC foam at elevated temperatures using digital image correlation. In: Proceedings of the 19th International Conference on Composite Materials. 2013: Montreal, Canada.

6. Zhang S, Dulieu-Barton JM, Thomsen OT. The effect of temperature on the failure modes of polymer foam cored sandwich structures. Compos Struct 2015; 121: 104-113.

7. Zhang S, Dulieu-Barton JM, Thomsen OT. The effect of elevated temperature on the bending behaviour of foam cored sandwich structures. Compos Mater 2015; 49: 3809822.

8. Palleti H, Zhang S, Fruehmann RK, Dulieu-Barton JM, Thomsen OT. Influence of thermomechanical interaction effects on the failure behaviour of polymer foam cored sandwich panels. J Sandw Struct Mater 2015; 17(3): 308-31.

9. Winkler E. Die lehre von der elastizität und festigkeit. Prague: 1867.

10. Thomsen OT. Theoretical and experimental investigation of local bending effects in sandwich plates. Comp Struct 1993; 25: 511-20

11. Thomsen OT. Localised Loads. In: An introduction to sandwich structures. Student Ed. Stockholm, 2005.

12. Olsson R. Engineering method for prediction of impact response and damage in sandwich panels. J Sandw Struct Mater 2002; 4: 2-29.

13. Frostig Y, Thomsen OT. Non-linear thermal response of sandwich panels with a flexible core and temperature dependent mechanical properties. Comp Part B 2008; 39(1): 16584. 
14. Laux T. Indentation failure of foam cored sandwich structures subjected to elevated temperatures. MSc Thesis, University of Southampton, UK, 2016.

15. PRF Composites. Prepreg systems RP-528 datasheet. http://www.prfcomposites.com (accessed September 2016).

16. E.J. Barbero. Introduction to composite materials. 1st ed. Boca Raton: CRC Press, 2005.

17. Gurit. SA 80 toughened epoxy adhesive film datasheet. http://www.gurit.com/files/documents/sa-80pdf.pdf (accessed September 2016)

18. Liu KS, Tsai SW. A progressive quadratic failure criterion for a laminate. Compos Sci Technol 1998; 58(7): 1023-32.

19. Engineering Toolbox. http://www.engineeringtoolbox.com/conductive-heat-transferd_428.html (accessed September 2016).

20. LaVision. DaVis Documentation, September 2016.

21. ANSYS. ANSYS Documentation, September 2016.

22. Jones R, Xenophontos J. The Vlasov foundation model. Int J Mech Sci 1977; 19(6): 31723. 